\title{
Broadening and deepening or broadening versus deepening: The question of enlargement and Europe's 'hesitant Europeans'
}

\author{
JEFFREY A. KARP ${ }^{1} \&$ SHAUN BOWLER ${ }^{2}$ \\ ${ }^{1}$ Texas Tech University, USA and University of Twente, The Netherlands; ${ }^{2}$ University of \\ California-Riverside, USA
}

\begin{abstract}
The European Union sees the inclusion of many Eastern European states enlargement - as a natural progression in the process of building an 'ever closer union'. For the European Commission in particular, the process of enlargement (broadening) is part of the process of integration and acts as a complement to the development of a stronger role for the European Union and its institutions or deepening of integration. Yet as the first Irish referendum on the Nice Treaty showed, not all of European's citizens see the two processes of enlargement and integration in the same light. This article addresses two related questions. First, how are attitudes towards deepening and broadening related, and do European citizens see them as complementary or contradictory? Second, and related to the first, what factors drive popular attitudes towards enlargement?
\end{abstract}

\section{Introduction}

The European Union (EU) sees the inclusion of many Eastern European states - enlargement - as a natural progression in the process of building an 'ever closer union'. For the European Commission in particular, the process of enlargement (broadening) is part of the process of integration and acts as a complement to the development of a stronger role for the EU and its institutions or deepening of integration (see European Commission, 2003). Yet as the first Irish referendum on the Nice Treaty showed, not all of the EU's citizens see the two processes of enlargement and integration in the same light. In June 2001, Ireland's voters (among the more enthusiastic pro-Europeans) defeated the Nice proposals to revise European's institutions in light of enlargement by a margin of 54 to $46 .{ }^{1}$ At least in some instances, then, some Europeans do not see enlargement and integration within the EU as complementary; rather, they see that one may pose a threat to the other. How general is this sense that broadening and deepening may not be two aspects of the same process, but two different processes? Furthermore, if they are seen as two different processes, what leads citizens to support or have doubts about those processes? 
We will examine in this article models of citizen opinion towards both broadening (enlargement) and deepening (further integration in existing policy areas). We find that attitudes towards the two processes do overlap, but are also distinct in ways that allow us to identify several broad groups. Alongside ardent pro-Europeans and ardent anti-integrationists, we are able to identify a third group that we label 'hesitant Europeans'. This is a group of some interest. Unlike others, they have not already made up their minds about the European project one way or the other, but occupy a middle category: citizens who may be generally supportive of integration, but are not yet persuaded of the virtues of current developments. It is not yet clear whether these doubts will lead this middle group to develop into ardent integrationists or ardent anti-integrationists. What is clear is that many of the doubts are tied to instrumental and, to some extent, institutional evaluations of the EU.

\section{Attitudes towards European integration}

In May 2004, following accession negotiations that began in the late 1990s, the EU achieved an historic transformation, expanding from 15 to 25 Member States, and thereby increasing its population by a fifth and its surface area by a quarter. The new Member States range from the tiny (Malta) to the large (Poland); eight of the ten new members are former communist countries (Czech Republic, Estonia, Latvia, Lithuania, Hungary, Poland, Slovakia and Slovenia) and two others (Bulgaria and Romania) are expected to join by 2007. ${ }^{2}$ Other possible entrants include the Balkan countries and Turkey.

Not all Europeans are especially welcoming to these new entrants. One interpretation of the enlargement issue is that it is a test of the depth of support for integration in general. For years, opinion towards the EU was seen in terms of a 'permissive consensus'. While popular support may not have been very high, outright opposition, a possibly more important set of opinions, was often quite low since many aspects of integration seemed of little or no relevance to voters or national political systems (see, e.g., Westle 1995). However, as integration moves into policy areas such as a single currency and seeks to allow many more countries into the club, the EU is no longer of low salience. At this point, the passive permission of voters may grow into opposition. The political relevance of that opposition was seen in the Irish rejection of the Nice Treaty.

How, then, are we to understand popular opinions towards enlargement in light of previous work on public opinion towards Europe? One possibility is that responses towards enlargement will simply follow a variant of existing patterns. One set of factors underlying responses to the EU is the presence 
or absence of a sense of European identity. Rather than being grounded in instrumentalist evaluations support for integrationist policies such as enlargement can, and for Euro-federalists should, be attached to an underlying commitment to the idea of Europe. A consistent pattern of results have shown that younger and better educated voters see themselves not so much as members of a particular national group, but as Europeans (see, e.g., Duchesne and Frognier (1995) and, for discussion in relation to post-materialism: Janssen (1991)). This kind of pan-European nationalism, then, is likely to be associated with support for enlargement while nationalism - and possibly right-wing ideology - should motivate hostility towards enlargement. An even simpler way of phrasing this is to posit that if voters are already against the EU they will not be in favour of enlargement. On the other hand, if they are already predisposed towards the EU they are likely to favour enlargement as part of the move towards integration. While a strong version of this argument would see support for enlargement as an affirmation of a pan-European nationalism, a weaker version would see attitudes to enlargement in terms of the "permissive consensus' we mentioned above. Respondents to enlargement as a specific issue in general or in the abstract will apply a general, even fuzzy, regard for Europe.

Here, the idea of a European identity may work in two ways. Doubts about integration may be tied to the respondent's own lack of a European identity and his or her misgivings about an 'ever closer union'. Or, perhaps, doubts about new entrants could be tied to the respondent's doubts that the new entrants are sufficiently European. It is not the respondent who is or is not European, but the new entrants who may not be seen as being European. For some, then, the broadening of the EU to embrace Eastern Europe may not, for citizens, be the same as deepening since Slovakians and Turks may not be seen as 'real' Europeans. If respondents do indeed make a distinction between broadening and deepening, then that fact alone suggests a different process of opinion formation than a 'permissive consensus'.

A second set of explanations for attitudes towards enlargement comes from the literature on popularity functions and the EU (see, e.g., Eichenberg \& Dalton 1993; Anderson 1998; Gabel 1998; Gabel \& Palmer 1995; Gabel \& Whitten 1997; Hix 1999). In this literature, opinion towards Europe is driven by a healthy component of self-interest. Employment in certain sectors of the economy that are expected to do well from EU membership is associated with support from the EU, as is being a citizen of a state benefiting from net transfers (Eichenberg \& Dalton 1993; Carrubba 1997). Similarly, not being in a state seen to benefit in such a material manner from the EU may well be associated with low support for integration (e.g., Smith \& Wanke 1993; Gabel 1998; Banducci et al. 2003). Leaving aside the question of whether these perceptions are primarily driven by concerns over pocketbook or sociotropic 
(national level) benefits, the findings consistently show a strong and relatively narrowly defined streak of self-interest underlying attitudes towards the EU. In which case, responses towards enlargement are likely to be driven by short-term instrumental concerns such as, for example, a concern over how the entry of new countries may provide additional benefits or costs. Following this line of reasoning, attitudes toward enlargement are likely to depend on what countries are being considered; wealthier countries are expected to enjoy greater acceptance than poorer countries.

Concern over how subsidy patterns will shift is also likely to shape attitudes toward enlargement. Some regions (e.g., in Ireland and in some areas in Spain and Italy) may, after enlargement, no longer be eligible for EU regional subsidies. Similarly, EU farm subsidies my well flow away from West European farmers and towards those in Eastern Europe after enlargement, possibly upsetting cozy deals made under the Common Agriculture Policy (CAP). In which case, we are likely to see stronger opposition to enlargement in the poorer countries of the EU 15 and among affected populations, most notably farmers. On the other hand, taxpayers in richer countries may well be reluctant to countenance enlargement since they know they will likely be asked to stump up yet more subsidy payments. Assessments of economic circumstances - personal and/or national - may thus be tied to assessments of enlargement: citizens going through tough economic times may want little or nothing to do with enlargement (Gabel \& Whitten 1997; Gabel \& Palmer 1995).

A third and much newer strand emphasizes the increasing importance of the EU's institutions in shaping attitudes about integration. As the EU has developed, its policies have become increasingly more likely to affect the everyday lives of its citizens. As a consequence, there is growing public concern about the EU's ability to be responsive to citizen demands. For example, Karp et al. (2003) find that concerns about the democratic deficit and dissatisfaction with the EU's current institutional framework serve to shape attitudes about it. Similarly, Rohrschneider (2002) finds that concerns about the quality of the democratic process constitute a serious liability to Europe's political integration. In this more evaluative view, voters use assessments of EU institutions and their performance to shape evaluations of more specific policies and developments. That is, rather than simply reflecting either blind dislike or blind support for any kind of integration, responses towards enlargement could reflect an assessment of how well the current EU is managing or how well they expect a new European settlement will work. Under this view, voter assessments will be framed in terms of the EU's own abilities and competencies implying that voters do see the EU as an important and legitimate political institution. In that sense, broadening and deepening may not be seen in the same way by voters if, for example, they 
believe that adding new members will make current institutional structures unworkable.

Re-stating the preceding discussion in different terms allows us to pose a series of questions. First, does the same model describe reactions to the two faces of the European project - that is, do people see broadening and deepening in the same way? Second, if people do make a distinction, then what factors lead them to embrace one and not the other - especially for those who support deepening but not broadening? Based on the preceding discussion, there are three sets of explanations for why citizens might be reluctant to embrace enlargement, two from the established literature on public opinion on integration (at least as defined to date in terms of deepening) and one that is newer.

1. European orientations: People who express doubts are those who have a strong sense of national identity/or weak sense of European identity.

2. Instrumental self-interest: A 'euros and cents' concern that the new entrants will take away benefits such as farm subsidies or jobs.

3. Institutions: Concerns about the effectiveness of Euro-institutions that stand apart from identity politics or narrow self-interest.

If voters see the processes of broadening and deepening as complementary, then the same model will describe public opinion whether our dependent variable is attitudes towards deepening or enlargement. On the other hand, there is scope for responses to enlargement and to deepening not to coincide as illustrated in the $2 \times 2$ typology displayed in Figure 1 . The main diagonal is the pattern in which voters see the two processes in the same way: Eurosceptics will oppose both broadening and deepening while Europhiles are likely to support both broadening and deepening. In which case, popular attitudes to enlargement conform to what we already know about popular attitudes towards European integration. On the other hand, and of far more interest, are the off diagonal elements in which we see those who we have labeled 'hesitant Europeans' who for various reasons may oppose either broadening or deepening, but not the other.

The existing literature on citizen opinions towards the EU can speak to the main diagonal elements: the lack (or presence) of a strong sense of nationalism or the role of self-interest can push people one way or the other. Yet these kinds of arguments cannot account for a more conditional acceptance of the EU. Either people are nationalistic - and hence reluctant to support the EU or they are not. The off-diagonal elements in Figure 1 suggest a more conditional process at work: citizens are supportive of deepening, but not broadening. In order to explain these off-diagonal opinions elements, we 
therefore have to bring to bear additional arguments. Here we suggest that what we have termed 'hesitant' or 'conditional' Europeans can be understood in terms of the third category of explanation we outlined above - namely that voters evaluate the effectiveness of EU institutions and then express support or opposition to enlargement. Part of the reason for this is that existing explanations are good at helping us understand opinions that fall on the main diagonal, but that if voters make distinctions between broadening and deepening, then these are not well explained by existing arguments since they represent a much more conditional voter response. We suggest that the reasons for conditional support will include the instrumental reasons that we suggest above - namely citizens who believe that enlargement would bring economic growth, but are reluctant to embrace initiatives such as the euro would fall into the upper left-hand side of the typology. For example, the citizens in those countries outside the euro zone (Britain, Denmark and Sweden) may oppose the euro, but support expansion. On the other hand, a concern about the loss of subsidies might make a citizen oppose broadening but favour deepening. Aside from these material benefits, citizens who have concerns about the loss of their country's influence in the EU may be likely to favour a more cohesive but limited union. One of the major implications of the Nice Treaty, for example, lies in institutional reforms needed in order to accommodate those new members. For example, one of the important reforms was an extension of majority voting in the Council that would presumably imply current members

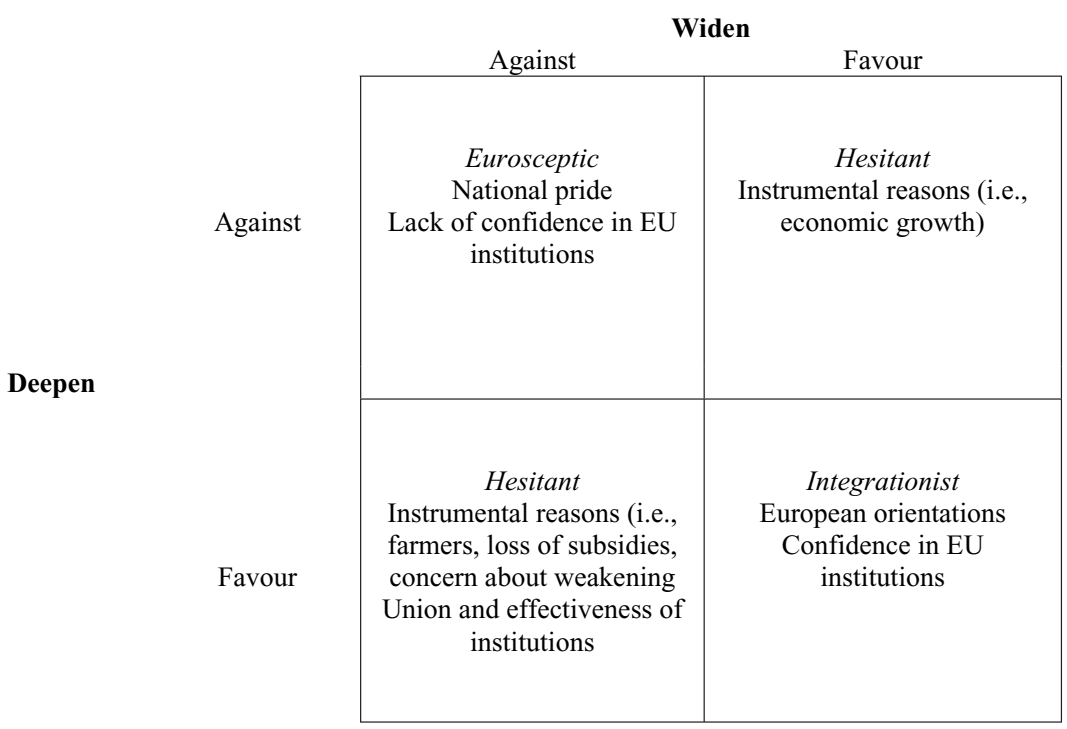

Figure 1. Expectations about preferences for European integration. 
being out-voted more often. One other aspect was that the bigger countries would gain more votes in the Council suggesting that smaller countries would have less say. Others who may fall into the hesitant category are those who support deepening but believe that the EU's institutions must be reformed to cope with a larger union.

Our empirical work proceeds in three steps. First, we examine the distribution of opinions according to the typology set out in Figure 1. We also examine whether support for enlargement depends simply on what countries are being considered. For some voters, one important rival hypothesis to the question of enlargement is not so much a matter of 'yes or no?' but 'who?'. In other words, some new entrants may be seen as acceptable while others may not. Not surprisingly, we find that substantial numbers of voters lie on the off-diagonal and, to a large extent, opposition or support of new entrants does not hinge crucially upon the identity of the new entrants. Having made these two points, we then turn to consider the factors that influence aspects toward broadening and deepening in light of the arguments outlined above. Our analysis relies on data from Eurobarometer 54 conducted in November and December 2000 in each of the 15 Member States. In addition to the standard questions used in the Eurobarometer, this data set has the advantage of including several measures of attitudes toward European integration as well as more specific questions measuring opinion about the entry of as many as 17 specific countries.

\section{The Hesitant Europeans}

As an initial assessment of the relationship between attitudes about broadening and deepening, we rely on two questions that ask respondents whether it should be a priority to welcome new members (broaden) and implement the single common currency (deepen). As Table 1 shows, there is greater support for deepening than broadening; 59 percent believe it should be a priority to implement the common currency, while just a third believes that it should be a priority to broaden the EU. As we can see from Table 1, Europeans divide into three camps: one staunchly pro-European, who comprise about a quarter of the total; one staunchly anti-European, which also comprises about a quarter; and a large middle group. Of those in the middle, about 20 per cent can be considered unsure either about deepening or widening. This leaves a considerable proportion that can be considered hesitant, expressing either a desire for broadening or deepening. In the analysis that follows, we explore the factors that influence these attitudes. While it may be too strong to talk about a trade-off between opinions, it seems to be the case that a pro-integration 
response does not always translate into support for more members. It would not be terribly surprising to learn that voters who oppose the EU are likely to oppose enlargement. It is a little more surprising, however, to learn that pro-European feeling does not always translate into support for enlargement. This group in particular could present a problem for the EU, and a potentially serious one.

\section{Attitudes about including specific countries}

An aggregate-level analysis can take us some way toward understanding how citizens in the EU view the inclusion of other countries. If attitudes toward expansion are based on economic self-interest, richer countries should enjoy greater acceptance than poorer countries. We might also hypothesize that these attitudes will vary across the EU. Support is likely to be lower when the difference in economic development between a candidate country and a Member State is greatest. In addition to economic wealth, we also examine whether support depends upon whether a country shares European values as measured by a country's respect for political rights and civil liberties. For our analysis, we have selected a total of 12 countries that include the candidate countries that either subsequently joined the EU in 2004 or those, as in the case of Bulgaria and Romania, who officially applied for membership. Freedom House ratings are used to measure a country's support for political rights and civil liberties.

Table 2 presents the results of a series of regression models estimated in each of the 15 Member States. For the most part, the results suggest that popular support for admission does not depend on the characteristics of the applicant countries. Wealth is only a significant factor in three countries, but the sign is only in the expected direction for Belgium. In Denmark and Sweden, support is higher for countries where the economic gap is largest.

Table 1. Distribution of preferences for broadening versus deepening

\begin{tabular}{lcccr}
\hline & Do not Broaden & Unsure & Broaden & Total \\
\hline Do not Deepen & 23.0 & 2.6 & 7.9 & 33.5 \\
Unsure & 1.8 & 5.1 & 1.1 & 8.0 \\
Deepen & 30.6 & 4.7 & 23.3 & 58.5 \\
Total & 55.4 & 12.3 & 32.2 & 100.0 \\
\hline
\end{tabular}

Note: Based on questions about whether it should be a priority to implement common currency and welcome new members. 


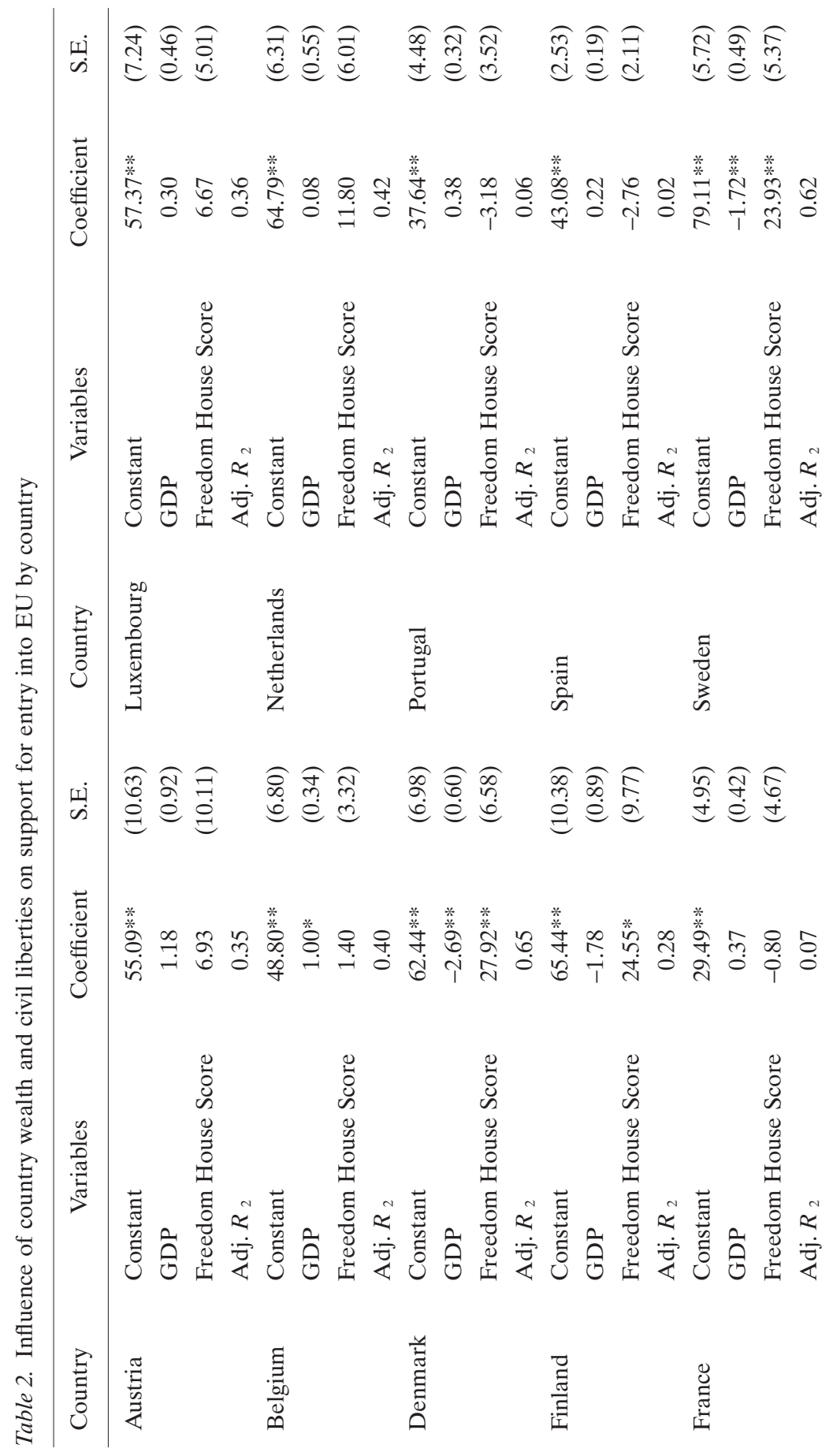




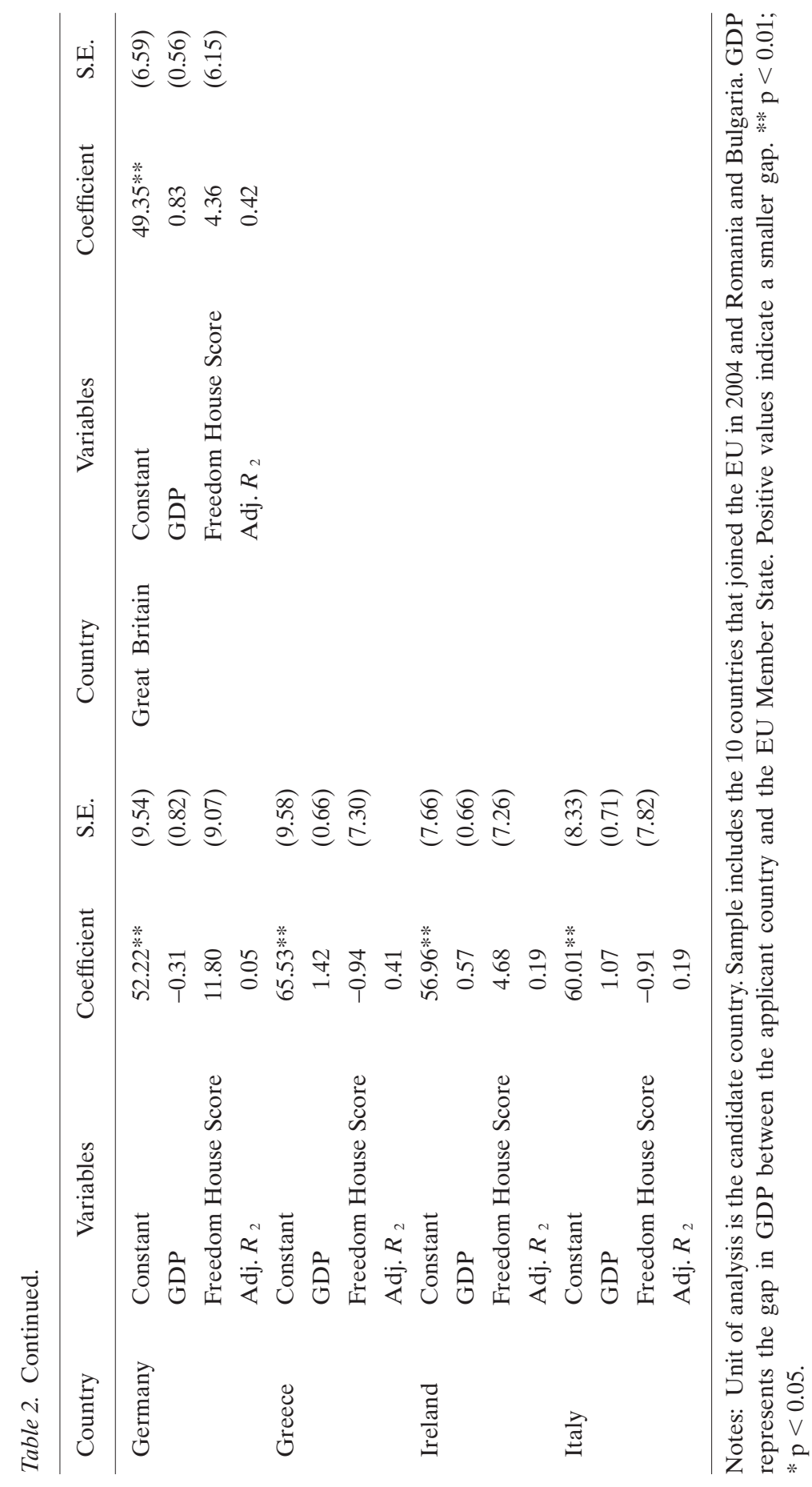


Clearly, citizens have concerns over enlargement that are not completely driven by concerns about poverty. The effect of political rights and civil liberties is more consistent, but is limited to three countries (Denmark, Finland and Sweden). Denmark and Sweden appear to place the most emphasis on rights and liberties and the overall fit in both these countries is high: 0.65 and 0.62 , respectively. For most of the other Member States, the characteristics of the applicant countries do not seem to matter. Instead, some citizens would seem to have objections to or doubts about the very principle of enlargement. The question is to what extent do attitudes toward enlargement simply reflect attitudes toward European integration in general?

\section{A model explaining attitudes toward broadening and deepening}

We proceed by estimating a model that tests the arguments discussed above. We constructed a single measure of deepening based on a summated scale from four questions that state specific policy objectives for the EU. These include the development of a common defence policy, the development of a common foreign policy, and two questions about the implementation of a single currency. None of these questions involve the accession of new members, but all would involve an expansion of EU power and influence into new areas (alpha $=0.72)$. To measure support for enlargement, we rely on two other items in Eurobarometer 54 that concern enlargement and do not mention the expansion of powers for the EU - just an expansion of members $($ alpha $=0.61)$. So that the two models are comparable, this scale has been divided by two, ranging from -2 to +2 (see Appendix for question wording).

To measure European orientations, we rely on a measure of European identity and ideology. We also include a question asking whether respondents express fears about the loss of national culture. We might also anticipate that citizens who reside in the original six Member States will have quite different views and expectations of European integration than citizens from countries that entered later. Countries outside the euro zone are likely to be more sceptical about integration, so a dummy variable is used to control for these effects.

We rely on several measures to examine the role of self-interest. Concerns over benefits and costs of EU membership can be measured in a number of ways. The Eurobarometer typically asks respondents to assess whether their country benefits in the following way: 'Taking everything into consideration, would you say that (our country) has on balance benefited or not from being a member of the European Union?' Note that this question asks individuals to evaluate the overall benefits of membership (which might also include trade, 
monetary stability and economic growth), rather than simply the direct net benefits that accrue from the EC budget (see also Anderson 1998; Gabel 1998; Eichenberg \& Dalton 1993: 514). A more narrow and objective indicator of specific costs and benefits can be determined by calculating the ratio of total payments to EU to receipts (Begg \& Grimwade 1998). Excluding spending by the EU on administration, Germany has always been a significant net contributor. Other net contributors include Belgium, the Netherlands, Austria, Sweden and the United Kingdom. Greece, Spain, Ireland and Portugal are identified as net beneficiaries. We also include a term for farmers, a group most readily identifiable as being affected by enlargement. Finally, population size is used to test the hypothesis that bigger countries will see their influence diluted by a larger EU.

To evaluate how the performance of the EU influences support, a measure of institutional confidence is used that is based on a series of questions about trust in EU institutions. ${ }^{3}$ One of the concerns of enlargement is that it will clog already slow-moving institutions. If citizens think the institutions cannot cope with more members, they are likely to oppose enlargement. It is important to note that this set of concerns represents an evaluative response to the EU as a political system. To evaluate the level of dissatisfaction with the EU's democratic performance, we use a question asking respondents to evaluate their satisfaction with democracy in the EU. Although there has been some controversy over its validity, most recent studies agree that it is a measure of support for regime performance (Linde \& Ekman 2003; Karp et al. 2003). Finally, we include a series of control variables (age, education, gender), all aimed at controlling for spurious relationships.

The Eurobarometer data are based on samples of individuals residing in 15 countries. Because of the multilevel structure of the data, most conventional methods of estimation will underestimate standard errors leading to a higher probability of rejection of a null hypothesis. Therefore, we proceed by estimating models using robust standard errors clustered by country. The procedure does not affect the coefficients, but it does estimate more consistent standard errors even when some of the assumptions about variance are violated.

\section{Results}

Results from this analysis are reported in Table 3. Many of the results are straightforward and we can see similarities across the models. Pro-European sentiment is, as we expected, correlated with support for both enlargement and deepening. The effects of European identity carry the same sign in both models and have similar effects. This is consistent with the pattern seen in Table 1: 
Table 3. Explaining attitudes toward broadening and deepening (OLS coefficients)

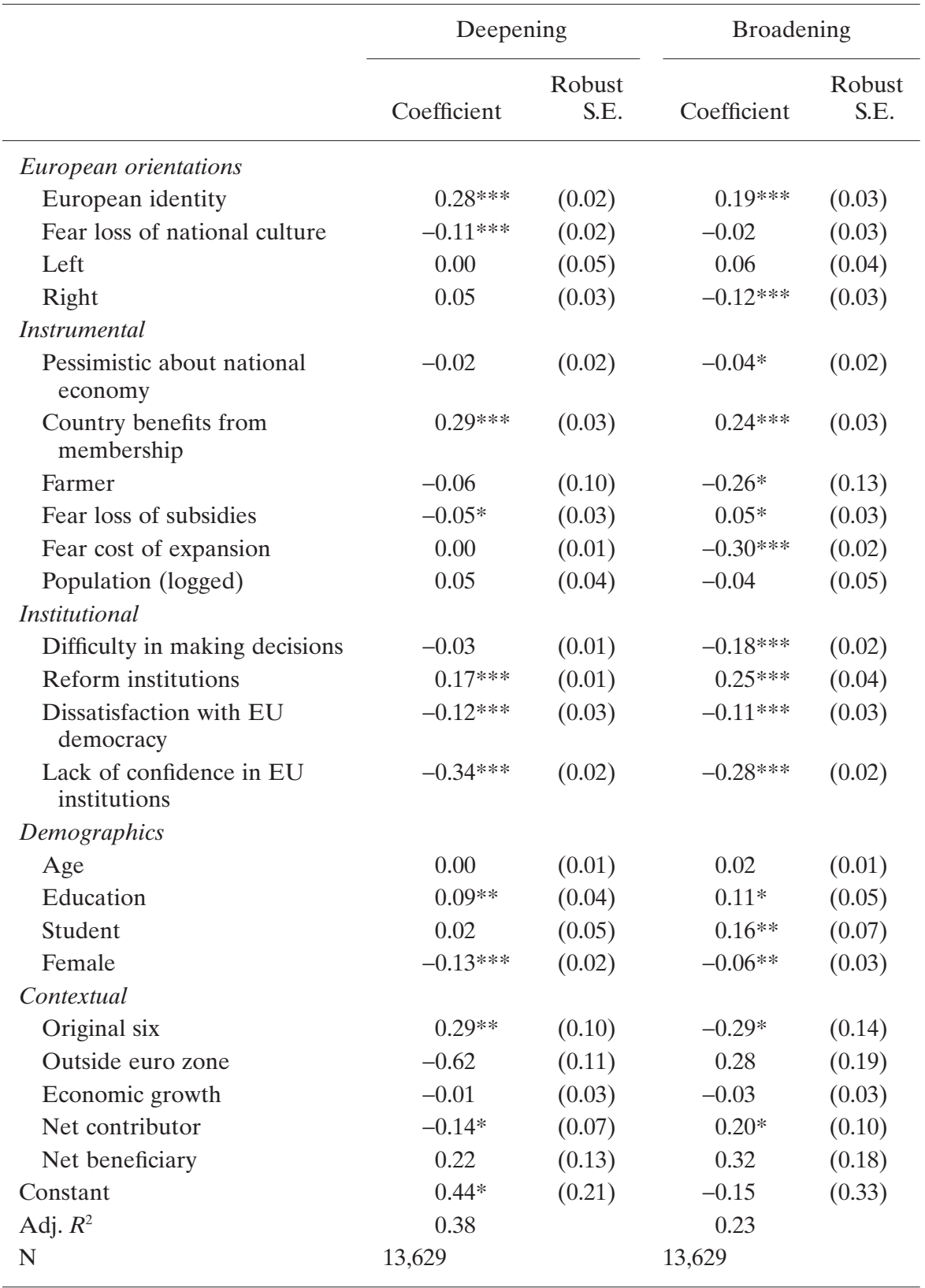

Notes: Robust standard errors are clustered by country. *** $\mathrm{p}<0.01$; ** $\mathrm{p}<0.05$; $* \mathrm{p}<0.10$.

Source: Eurobarometer 54, November-December 2000. 
one bloc of voters are ardent pro-Europeans and another bloc ardent antiEuropeans and so will support or oppose a range of issues. We also find that concern about EU democracy and a lack of confidence in institutions weakens support for both deepening and widening. With one exception, all four measures are statistically significant in both models and all have the same sign. Education also has a positive impact on both aspects of integration, though the impact is much larger on support for broadening.

We also see a number of sign changes that are especially important since these are the group of voters that is much more hesitant in their support of integration. Specifically we see that those on the right side of the ideological continuum are against enlargement even though there are no ideological differences on deepening. Similarly, the question of enlargement elicits a negative response from both farmers and those respondents who fear the cost of expansion. These last patterns are consistent with highly self-interested motivations in relation to enlargement: enlargement threatens their benefits. Citizens from countries that are net contributors are less likely to favour deepening and more likely to favour broadening, presumably due to an expectation that other countries may lessen the burden. We expected citizens from larger countries to be more sceptical about enlargement than smaller countries. While the sign is in the expected direction, it is not statistically significant. The dummy variable representing length of experience in the EU clearly reflects different priorities. Citizens from the original six Member States are more supportive of deepening but less supportive of widening.

The findings above suggest that attitudes about enlargement may not be the same as attitudes about deepening. To examine this question more thoroughly, we employ a multinomial logit model to test support and opposition for a combination of specific policy proposals. The dependent variable is based on cumulative responses to whether it should be a priority for the EU to implement the common currency and/or enlargement (as in Table 1). The same independent variables used above are included in the model. The results are reported in Table 4. To ease the interpretation of the coefficients, we also report the derived probabilities for each of the outcomes in Table 5. To assess the relative strength of the three explanations, we estimate the probability for each outcome when all of the variables within each category are set at their minimum and maximum values. Institutional concerns appear to create resistance about whether either policy should be a priority rather than a preference for one policy over another. In comparison, instrumental concerns have a relatively strong impact in creating opposition to enlargement, while supporting further deepening. Specifically, the likelihood of opposing enlargement but supporting the common currency increases from 0.26 to 0.46 when all of the instrumental variables are set at their maximum. As the results in Table 4 show, 


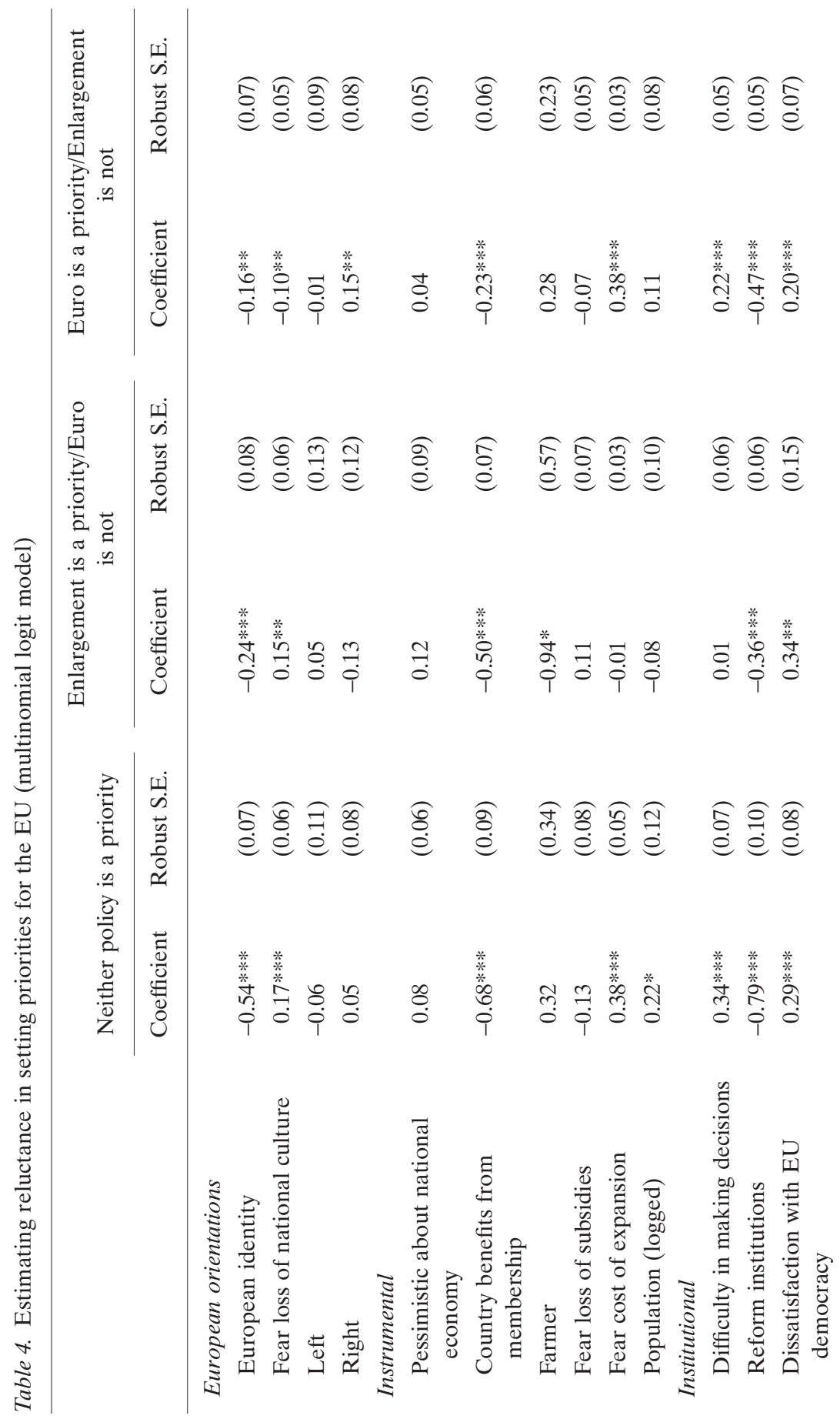




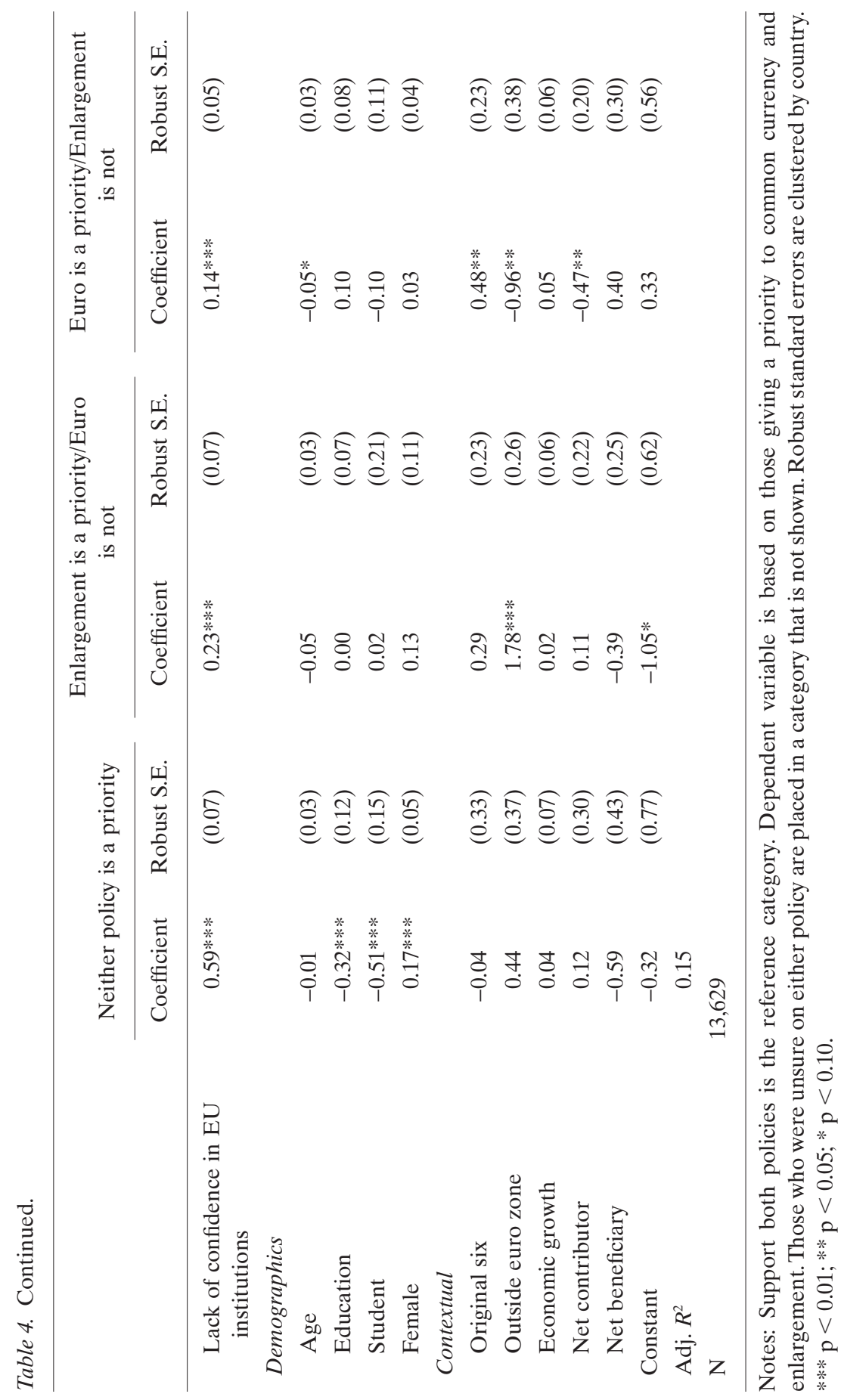




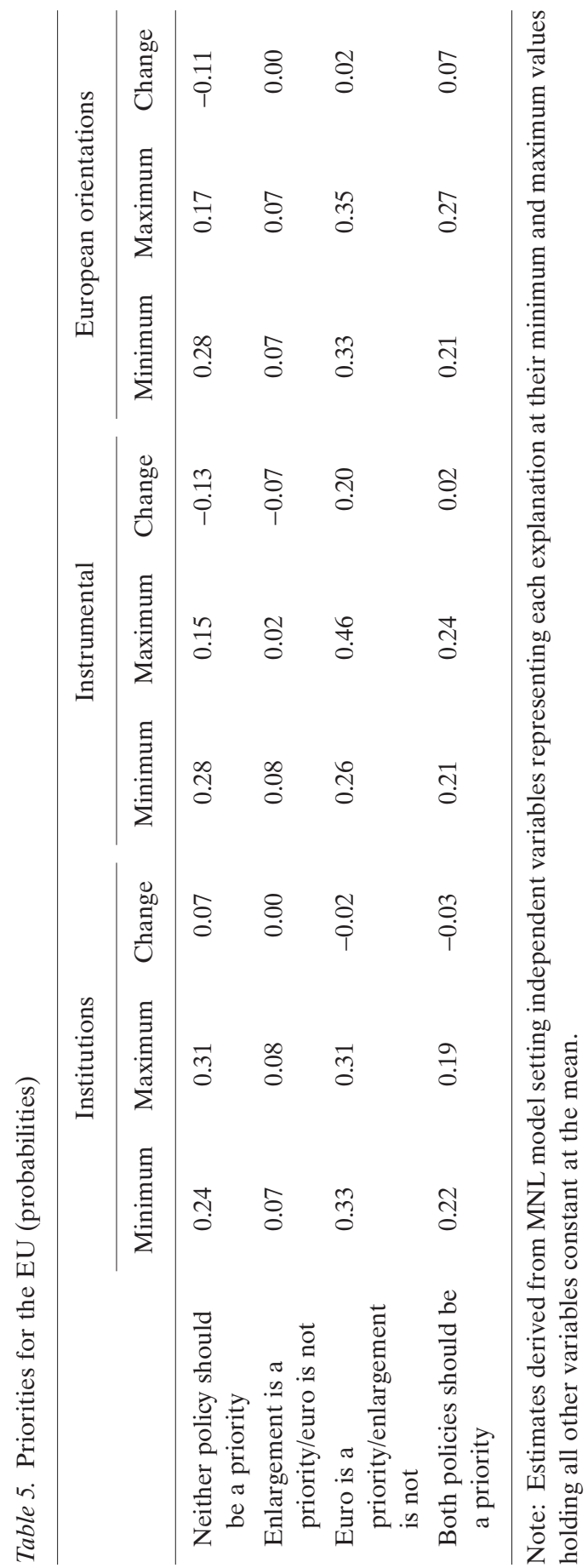


fear of the cost of expansion is one of the main factors driving these results. Finally, European orientations appear to lead citizens to support both aspects of integration, though the overall impact is rather small.

\section{Discussion}

The evidence presented thus far points to the conclusion that attitudes toward European integration are multidimensional. While there is a group of citizens who are either strong supporters of integration, whether directed toward deepening or widening, and another group that is opposed to both aspects of integration, the largest group of Europeans remains hesitant about European integration, either expressing support or opposition for either deepening or widening. Our analysis suggests that their reluctance to either oppose or support both aspects of European integration is not caused by ambivalence, but rather is influenced in ways that are consistent with instrumental selfinterest and EU performance. This has implications for the legitimacy of the European project as it indicates that citizens are beginning to evaluate the EU in terms of what it has delivered, rather than something that remains highly remote and abstract.

The enlargement to the East offers both opportunities and challenges to the building of the EU. For the Commission, enlargement almost seems to be a natural step or stage in the evolution of integration. And for many European citizens this also seems to be the case. Yet the Commission should not be too quick to celebrate. One of the major drivers of public opinion towards the EU is that of self-interest. Up until now, the EU has been able to rely on a series of instrumental arguments that favour the EU itself - the arguments (made both by the EU and national politicians) that membership means increased trade, increased jobs and, in some instances, increased subsidies and price supports and development funds. All of these played their part in building support for the EU. And the EU itself seems to have spent many years trying very hard to get Europe's voters to take it seriously as a meaningful institution. Now, however, enlargement may well bring those arguments into play in the opposite direction and the argument of self-interest works against the EU's agenda even as it shows that voters are beginning to accept the EU as an important and meaningful part of the political landscape. Voters, attuned to the benefits of EU subsidy, now understand they may lose something of value via enlargement. Instrumental motivations may now work against the EU. The good news from the point of view of the Commission is that this at least shows the development of legitimacy for EU. The bad news is that the very same 
self-interested motivations that have helped build support for the EU now may help weaken support for the next stage of integration.

\section{Appendix}

\section{Dependent Variables}

I am going to read out a list of actions that the European Union could undertake. For each one, please tell me, if in your opinion, it should be a priority, or not?

Successfully implementing the single European currency, the euro (Table 1, Deepening Table 3 and Table 4)

Welcoming new member countries (Table 1, Broadening Table 3 and Table 4)

For each of the following countries, would you be in favour of or against it becoming part of the European Union?

Czech Republic, Cyprus, Estonia, Latvia, Lithuania, Hungary, Malta, Poland, Slovakia, Slovenia, Bulgaria, Romania (Table 2)

What is your opinion on each of the following statements? Please tell me for each proposal, whether you are for it or against it. (ROTATE)

There has to be a European Monetary Union with one single currency, the euro (Deepening in Table 3)

The Member States of the European Union should have one common foreign policy toward countries outside the European Union (Deepening, Table 3)

The European Union Member States should have a common defence and security policy (Deepening, Table 3)

The European Union should be enlarged and include new countries (Broadening, Table 3)

\section{European Orientations}

'Would you say you are very proud, fairly proud, not very proud, not at all proud to be a European?' (European identity) 
"In political matters people talk of "the left" and "the right". How would you place your views on this scale?' [ranging from 1 to 10] (Left 1-4; Right 7-10)

\section{Instrumental}

What are your expectations for the year to come: will 2001 be better, worse or the same, when it comes to...?

The economic situation in (OUR COUNTRY) (Pessimistic about national economy)

Taking everything into consideration, would you say that (OUR COUNTRY) has on balance benefited or not from being a member of the European Union? (Country benefits from membership)

Some people may have fears about the building of Europe, the European Union. Here is a list of things which some people say they are afraid of. For each one, please tell me if you - personally - are currently afraid of it, or not?

The loss of our national identity and culture (Fear loss of national culture) Less subsidies from the European Union for (OUR COUNTRY) (Fear loss of subsidies)

Other countries joining the European Union will cost member countries too much money (Fear cost of expansion)

\section{Institutional}

Thinking about the enlargement of the European Union to include new countries, do you tend to agree or tend to disagree with each of the following statements? (ROTATE)

With more countries, it will be much more difficult to make decisions on a European scale (Difficulty in making decisions)

I am going to read out a list of actions that the European Union could undertake. For each one, please tell me, if in your opinion, it should be a priority, or not?

Reforming the institutions of the European Union and the way they work (Reform Institutions) 
On the whole, are you very satisfied, fairly satisfied, not very satisfied or not at all satisfied with the way democracy works in the European Union? (Dissatisfaction with EU Democracy)

And, for each of them, please tell me if you tend to trust it or tend not to trust it?

The European Parliament, The European Commission, The Council of Ministers of the European Union, The Court of Justice of the European Communities, The European Ombudsman, The European Central Bank, The European Court of Auditors, The Committee of the Regions of the European Union, The Social and Economic Committee of the European Union (Lack of Confidence in EU Institutions)

\section{Notes}

1. A second referendum, held in October 2002, was approved by a margin of 63 to 37 per cent.

2. Cyprus also joined the EU in 2004.

3. Of all the EU institutions, the Court of Justice received the greatest confidence, but still more than half distrusted the institution. In contrast, just a quarter trusted the European Commission, while 36 percent said they could trust the European Parliament. While these aggregate differences may suggest that evaluation of each of the institutions varies across individuals, a common factor analysis suggests otherwise. A single, very strong factor emerges from the factor analysis, accounting for 80 per cent of the variance across the nine measures (eigenvalue 7.2). This strongly suggests that individuals tend not to distinguish one EU institution from another. In other words, those who distrust the EP are also likely to distrust other EU institutions. Initially each of the items was coded so that a negative value was associated with distrust and a positive value with trust. Individuals who are unaware of the institution or do not have an opinion were not included in these measures. Taking the mean response over all of the institutions forms a single index ranging from -1 to 1 .

\section{References}

Anderson, C.J. (1998). When in doubt use proxies: Attitudes to domestic politics and support for the EU. Comparative Political Studies 31: 569-601.

Banducci, S.A., Karp, J.A. \& Loedel, P.H. (2003). The euro, economic interests and multilevel governance: Examining support for the common currency. European Journal of Political Research 42(5): 685-703.

Begg, I. \& Grimwade, N. (1998). Paying for Europe. Sheffield: Sheffield Press.

Carrubba, C.J. (1997). Net financial transfers in the European Union: Who gets what and why? Journal of Politics 59: 469-496. 
Duchesne, S. \& Frognier, A.-P. (1995). Is there a European identity? In O. Niedermayer \& R. Sinnott (eds), Public opinion and internationalized governance. Oxford: Oxford University Press.

European Commission. (2003). Enlargement of the European Union: An historic opportunity. Brussels: European Communities.

Eichenberg, R.C. \& Dalton, R.J. (1993). Europeans and the European Community: The dynamics of public support for European integration. International Organization 47: 507-534.

Gabel, M.J. (1998). Public support for European integration: An empirical test of five theories. Journal of Politics 60: 333-354.

Gabel, M. \& Palmer, H. (1995). Understanding variation in public support for European integration. European Journal of Political Research 27: 3-19.

Gabel, M. \& Whitten, G. (1997). Economic conditions, economic perceptions and public support for European integration. Political Behavior 19(1): 81-96.

Hix, S. (1999). The political system of the European Union. New York: Palgrave.

Janssen, J.I.H. (1991). Post-materialism, cognitive mobilization and public support for European integration. British Journal of Political Science 21: 443-468.

Karp, J.A., Banducci, S.A. \& Bowler, S. (2003). To know it is to love it? Satisfaction with democracy in the European Union. Comparative Political Studies 36(2): 271-292.

Linde, J. \& Ekman, J. (2003). Satisfaction with democracy: A note on a frequently used indicator in comparative politics. European Journal of Political Research 42: 391-408.

Rohrschneider, R. (2002). The democracy deficit and mass support for an EU-wide government. American Journal of Political Science 46: 463-475.

Smith, D.L. \& Wanke, J. (1993). Completing the Single European Market: An analysis of the impact on the Member States. American Journal of Political Science 37(2): 529-554.

Westle, B. (1995). The view from within. In O. Niedermayer \& R. Sinnott (eds), Public opinion and internationalized governance. Oxford: Oxford University Press.

Address for correspondence: Jeffrey Karp, Department of Political Science, 113 Holden Hall, Texas Tech University, Lubbock, TX 79409, USA. E-mail: j.karp@ttu.edu or j.a.karp@ utwente.nl 